\title{
Fibrous Hamartoma Of Infancy
}

\author{
J Lane, M Beckish
}

\section{Citation}

J Lane, M Beckish. Fibrous Hamartoma Of Infancy. The Internet Journal of Dermatology. 2001 Volume 1 Number 2.

DOI: $\underline{10.5580 / 1 b 30}$

\begin{abstract}
Fibrous hamartoma of infancy is a rare, benign soft tissue tumor that typically occurs within the first two years of life. The histogenesis is unclear. It is most commonly found in the axilla, shoulder, inguinal region, and chest wall and is usually a solitary malformation located in the subcutaneous tissue or reticular dermis. Local recurrence is uncommon and treatment is largely successful by local excision. The clinical course is typically benign and prognosis excellent. We describe an 11-month-old male with a mass on his left thigh that progressively increased in size. The management of a subcutaneous mass in the pediatric patient presents a clinical challenge. The differential diagnosis includes numerous benign and malignant soft tissue tumors. The physical appearance and characteristics of a subcutaneous mass on a child may suggest a malignant process; however, FHI should be included within the differential diagnosis.
\end{abstract}

\section{INTRODUCTION}

Fibrous hamartoma of infancy (FHI) is a rare, benign soft tissue tumor that usually occurs within the first two years of life. The histogenesis of FHI is unclear. The clinical course is typically benign and prognosis excellent. We describe an 11-month-old male with a mass on his left thigh that progressively increased in size. The management of a subcutaneous mass in the pediatric patient presents a clinical challenge. The differential diagnosis includes numerous benign and malignant soft tissue tumors. The physical appearance and characteristics of a subcutaneous mass on a child may suggest a malignant process; however, FHI should be included within the differential diagnosis.

\section{CASE REPORT}

An 11 month-old male was brought to our office for evaluation of a mass on his left thigh. The mass had been present for several months and had increased in size. There was no interference with activity from the mass. The child had a normal delivery and no medical complications. Neither family nor social history revealed any pertinent findings.

Physical examination revealed a well-developed and wellnourished 11 month-old Caucasian male in no distress. Neurologic, cardiac, pulmonary, abdominal, and musculoskeletal examinations were all within normal limits. There was however, a $3 \mathrm{~cm}$ mobile mass proximal and medial to his left patella. The mass appeared extra articular on exam. There was no tenderness, erythema, or warmth associated with the mass. Range of motion, motor, and sensory examination of the left leg was normal.

Radiographic analysis of the mass revealed no bony pathology. The patient was brought to the operating room for an excisional biopsy of the left thigh mass. A longitudinal incision was made over the mass and the subcutaneous tissue was sharply divided. The mass was adherent to the overlying dermis, thus requiring dissection between the dermis and the mass. No communication between the mass and the knee joint was noted.

Gross examination of the mass revealed two lobulated fragments of yellowish tissue measuring $2 \times 1.5 \times 0.5 \mathrm{~cm}$ and $1.6 \times 1 \times 0.5 \mathrm{~cm}$. The mass was composed predominantly of fibrofatty tissue. Microscopic examination was indicative of fibrous hamartoma of infancy (Fig. 1 and 2). 


\section{Figure 1}

Figure 1. Characteristic histologic appearance of fibrous hamartoma of infancy demonstrating an admixture of mature adipose tissue, scattered primitive mesenchymal cells, and dense bundles of fibrous tissue (100x).

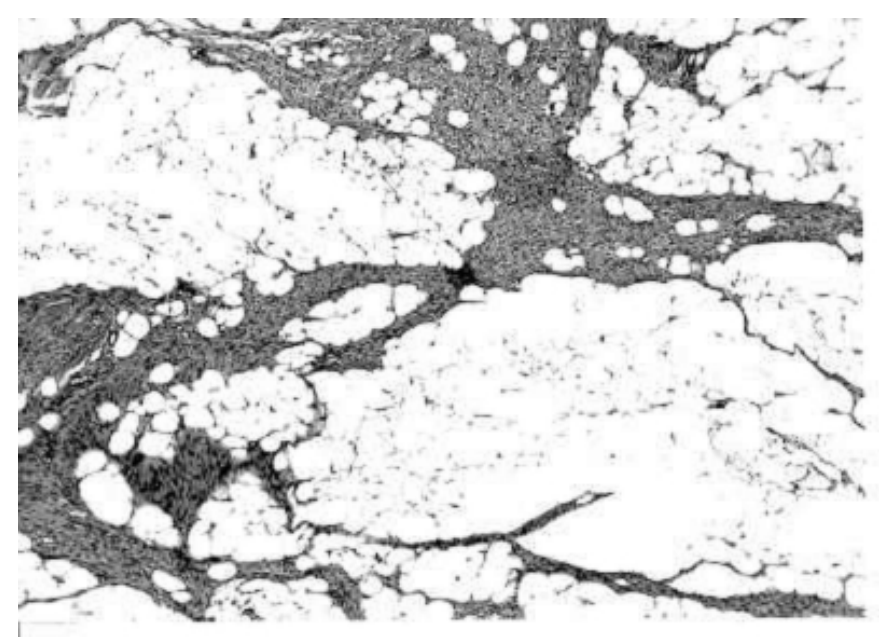

\section{Figure 2}

Figure 2. High power view demonstrating characteristic admixture of mature adipose tissue (400x).

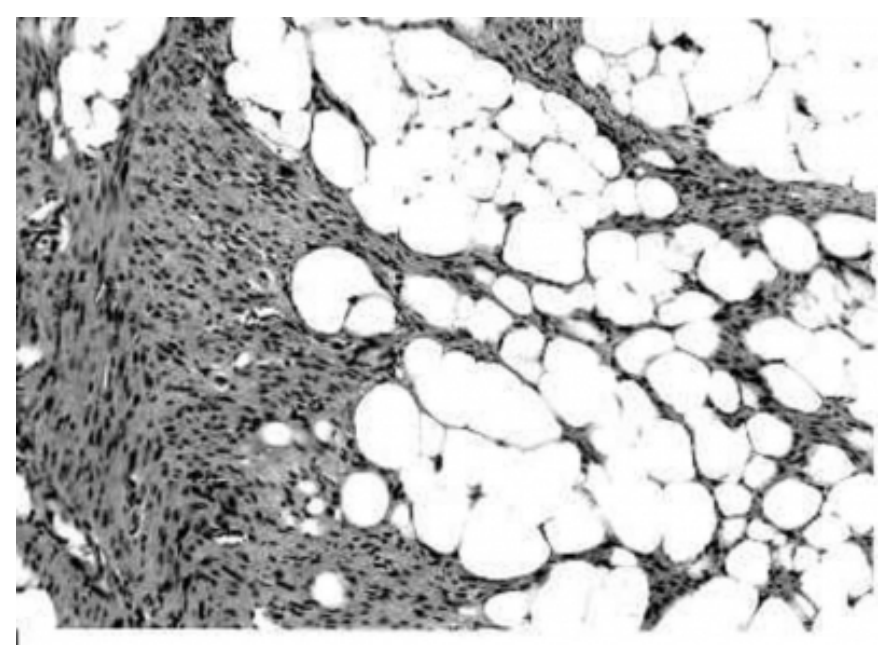

\section{DISCUSSION}

Fibrous hamartoma of infancy (FHI) is a rare, benign soft tissue tumor that usually occurs within the first two years of life. Fibrous hamartoma of infancy was first described by Reye in 1954 and later coined its current name by Enzinger. ${ }_{1,2}$ Males are affected more often than females and its histogenesis is unclear. $2,{ }_{3,4,5,6,5}$ Fibrous hamartoma of infancy is most commonly found in the axilla, shoulder, upper arm, inguinal region, and chest wall; however, isolated cases have been reported involving the foot, scalp, perianal region, gluteal region, and scrotum.4,5,6, It is usually a solitary malformation located in the subcutaneous tissue or reticular dermis. The lesions are typically 1 to $8 \mathrm{~cm}$ in diameter but have been reported up to $10 \mathrm{~cm} .6,7$ The tumor is usually firm and may be affixed to underlying tissue, thus causing concern of potential malignancy.7 Local recurrence is uncommon and treatment is largely successful by local excision. The clinical course is typically benign and prognosis excellent.7

There are several characteristic histologic features of FHI, including bundles of fibrous tissue, regions of mature adipose, and scattered primitive mesenchymal cells.1,4-8 Anaplasia is not seen and mitotic figures are uncommon.8 Ultrastructural studies have demonstrated the composition of FHI to include fibroblasts, myofibroblasts, primitive mesenchymal cells, small blood vessels, and mature adipocytes.4,9 Immunohistochemical studies of FHI support the ultrastructural findings. 4

Local recurrence rate is approximately $16 \%$ according to a study by Enzinger and may have been explained by incomplete excision of the lesion. 2 The clinical course of FHI is benign, as demonstrated by a study of untreated FHI by Efem and Ekpo.6 In this study with protracted and untreated FHI, the tumor capsule was more complete and well defined, which made surgical excision less difficult secondary to more distinct cleavage planes.6 Additionally, this study demonstrated that untreated FHI continues to grow without regression. Local excision is the treatment of choice for FHI; however, delayed surgery is not associated with an increased risk of operative complications.6

The management of a subcutaneous mass in the pediatric patient presents a clinical challenge. The differential diagnosis includes both benign and malignant soft tissue tumors. A number of entities are included within the differential diagnosis such as epidermoid cyst, recurring digital fibrous tumor, juvenile aponeurotic fibroma, juvenile hyaline fibromatosis, palmoplantar fibromatosis, histiocytoma, dermatofibroma, leiomyosarcoma, and fibrosarcoma ${ }_{10}$

In conclusion, the physical appearance and characteristics of a subcutaneous mass on a child may suggest a malignant process; however, FHI should be included within the differential diagnosis. Furthermore, the prognosis of such diagnosis is excellent and local surgical excision is effective with rare events of recurrence.

\section{CORRESPONDENCE TO}

Joshua E. Lane, M.D. Section of Dermatology Department 
of Medicine The Medical College of Georgia Augusta, GA 30912 Phone: (706) 721-6237 Fax: (801) 340-1519 E-mail: joshua.lane@1ycos.com

\section{References}

1. Reye RDK. A consideration of certain subdermal ffibromatous tumours $\llbracket$ of infancy. J Pathol Bacteriol 1956; 72: 149-154.

2. Enzinger FM Fibrous hamartoma of infancy. Cancer 1965; 18: 241-248.

3. Paller AS, Gonzalez-Crussi F, Sherman JO. Fibrous hamartoma of infancy: Eight additional cases and a review of the literature. Arch Dermatol 1989; 125: 88-91.

4. Groisman G, Lichtig C. Fibrous hamartoma of infancy: An immunohistochemical and ultrastructural study. Hum
Pathol 1991; 22: 914-918.

5. Sotelo-Avila C, Bale PM. Subdermal fibrous hamartoma of infancy: Pathology of 40 cases and differential diagnosis. Pediatr Pathol 1994; 14: 39-52.

6. Efem S, Ekpo MD. Clinicopathological features of untreated fibrous hamartoma of infancy. J Clin Pathol 1993; 46: $522-524$

7. Lee JT, Girvan DP, Armstrong RF. Fibrous hamartoma of infancy. J Pediatr Surg 1988; 23: 759-761.

8. Greco MA, Schinella RA, Vuletin JC. Fibrous hamartoma of infancy: An ultrastructural study. Hum Pathol 1984; 15: 717-723.

9. Aberer E, Mainitz M, Entacher V, et al. Fibrous hamartoma of infancy. Infantile subcutaneous myofibroblastoma. Dermatologica 1988; 176: 46-51. 10. Albukerk J, Wexler H, Dana M, Silverman J. A case of fibrous hamartoma of infancy. J Ped Surg 1979; 14: 80-82. 


\section{Author Information}

Joshua E Lane, MD

Resident, Department of Surgery, Division of Orthopedic Surgery, Mercer University School of Medicine

Michael L Beckish, MD

Clinical professor, Department of Surgery, Division of Orthopedic Surgery, Mercer University School of Medicine 